\title{
Autoantibody Profile and Its Association with Clinical Presentation of Paediatric SLE Patients
}

\author{
Kalyan Benjamin Gomes ${ }^{1}$, Mohammad Imnul Islam ${ }^{2, ~ *, ~ S h a h a n a ~ R a h m a n ~}{ }^{2}$ \\ ${ }^{1}$ National Institute of Cardiovascular Disease (NICVD), Dhaka, Bangladesh \\ ${ }^{2}$ Department of Paediatrics, Bangabandhu Sheikh Mujib Medical University, Dhaka, Bangladesh
}

Email address:

kalyangomes@gmail.com (K. B. Gomes),imon27@gmail.com (M. I. Islam), shahana2pd@yahoo.com(S. Rahman)

${ }^{*}$ Corresponding author

\section{To cite this article:}

Kalyan Benjamin Gomes, Mohammad Imnul Islam, Shahana Rahman. Autoantibody Profile and Its Association with Clinical Presentation of Paediatric SLE Patients. American Journal of Pediatrics. Vol. 5, No. 4, 2019, pp. 178-182. doi: 10.11648/j.ajp.20190504.11

Received: July 8, 2019; Accepted: August 12, 2019; Published: September 9, 2019

\begin{abstract}
Systemic lupus erythematosus (SLE) is a chronic autoimmune disease characterized by the production of various auto antibodies including anti-nuclear antibody, double stranded DNA and antibodies to extractable nuclear antigens (ENA), which include four groups of RNA binding protein namely Sm, RNP, SSA/Ro and SSB/La. The objectives were to detect the frequency and pattern of ANA, frequency of anti- ENA antibodies and association between the clinical presentations with ANA and Anti-ENA antibodies in paediatric SLE patients. It was a cross sectional study and the data was collected from patients fulfilling the ACR 1997 revised criteria of SLE in the Department of Paediatrics, BSMMU, Dhaka, Bangladesh. Among 50 paediatric SLE patients, ANA was positive in $94 \%$ of the patients. Homogenous pattern of ANA was the highest $(57 \%)$ followed by speckled (31\%), cytoplasmic (6.6\%) and nucleolar (3.3\%) patterns. Anti-ds DNA positivity was $86 \%$ and antiENA positivity was $56 \%$ in this study. Among them, anti-RNP was found in $43.5 \%$ followed by anti-sm (24\%), anti-SSA (24\%) and anti-SSB (17\%). Anti-RNP antibody was associated with renal and gastrointestinal and Anti-SSA was associated with only gastrointestinal manifestations. ANA, anti ds-DNA, anti ENA positivity were found significantly among paediatric SLE patients and clinical presentation of them had association with Anti-ENA antibodies.
\end{abstract}

Keywords: Extractable Nuclear Antigens (ENA), Systemic Lupus Erythematosus (SLE)

\section{Introduction}

SLE is a complex autoimmune disease with heterogeneous manifestations. The diagnosis of SLE is usually made when patients have 4 or more out of the 11 ACR criteria [1] which can range from different organ manifestations to production of various autoantibodies. Individual autoantibodies can reflect or predict disease activity, and some are associated with specific disease manifestations. [2, 3]. Compared with adults, children and adolescents with SLE have more severe disease and more widespread organ involvement. [4]. This autoimmune disease is characterized by the production of various autoantibodies directed against chromatin components and extractable nuclear antigens (ENA) including double stranded DNA (ds-DNA), and four groups of RNA binding protein namely Sm (Smith), RNP (ribonucleoprotein), SSA/Ro and SSB/La. [5]. Anti-nuclear antibodies (ANA) are specific antibodies directed against variety of nuclear antigens which have been found in more than $90 \%$ of the paediatric SLE patients. [6]. When ANA is detected by Indirect immunoflurescence (IIF) method, distinctive staining patterns in the nucleus or cytoplasm may be found. These staining pattern can be subdivided into homogenous (H-ANA), centromeric (C-ANA), speckled/ extrachromosomal (S-ANA), nucleolar (N-ANA), nuclear membrane, nuclear dot, cytoplasmic pattern and other defined patterns. [7]

Anti-Sm antibody is highly specific for SLE and has been reported to be associated with constitutional symptoms, nephritis and central nervous system disease. Anti-Ro and anti-La antibodies are present in neonatal and sub-acute cutaneous SLE especially with annular rash. [8]. Anti-RNP is associated with photosensitivity. [9]. Anti-ds DNA is highly specific for SLE and glomerulonephritis. [10]

Antibodies to ENA profile are the hallmark in the 
diagnosis of SLE and sometimes support to the diagnosis in spite of negative ANA in a SLE patients. [11] It may predict different organ involvement in SLE, which helps in early diagnosis and organ involvement as well as early initiation of appropriate treatment. No study so far has been done regarding ENA profile and its association with clinical manifestations in paediatric SLE patients in Bangladesh. The objectives of this study were to determine the frequency and pattern of ANA, frequency of ENA profile in paediatric SLE patients. Associations between ANA and Anti-ENA antibodies with clinical manifestations in SLE children were also assessed in this study.

\section{Methods}

This cross-sectional study was conducted in the Department of Paediatrics, Bangabandhu Sheikh Mujib Medical University (BSMMU), Dhaka from January 2015 to June 2016. Fifty newly diagnosed patients fulfilling the ACR 1997 revised classification criteria of systemic lupus erythematosus (SLE) were enrolled in this study. This study was approved by institutional review board (IRB) of Bangabandhu Sheikh Mujib University (BSMMU), Dhaka. Written consent was taken from the parents prior to inclusion in the study. Clinical characteristics and laboratory information were noted at initial visit and recorded in a preformed structured questionnaire.
ANA was detected by immunofluoresence (IF) method using HEp-2 cell line as substrate. The FLUORO HEPANA TEST kit was used for this test and staining pattern was identified by immunofluoresence microscope (Olympas $\mathrm{CH}$ 40). [12.] In the present study 1:160 dilution was considered positive for detection of ANA by IF method.

Blue DOT ENA IgG is an immunodot kit based on the principle of enzyme immunoassay, was used for detection of IgG auto antibodies against Sm, RNP, SSA (Ro), SSB (La), Jo and Scl 70 antigens. [13]. Statistical analysis was done using Statistical Package of Social Sciences (SPSS) for windows version 20 and $\mathrm{p}$ values of less than 0.05 were considered statistically significant.

\section{Result}

A total number of 50 paediatric SLE patients were enrolled in this study. Females were the majority $(84 \%)$ in this series and age at the time of disease onset was $12.46 \pm 2.33$ years. Mean disease duration was $9.46 \pm 11.04$ months. Among clinical presentations, fever was found in the majority (92\%) of SLE patients followed by fatigue (82\%), arthritis/ arthralgia $(76 \%)$ and non-specific rash $(72 \%)$. Proteinuria (60\%), photosensitivity (54\%), oral ulceration (54\%) and hepato-splenomegaly $(46 \%)$ were also present in these patients (Table 1).

Table 1. Different clinical presentations among the childhood SLE patients. $(n=50)$.

\begin{tabular}{llll}
\hline Clinical features & & Number (n) & \% \\
\hline \multirow{3}{*}{ Constitutional } & Fever & 46 & 92.0 \\
& Fatigue & 41 & 82.0 \\
& Anorexia & 22 & 44.0 \\
Musculoskeletal & Lymphadenopathy & 14 & 28.0 \\
& Arthritis /arthralgia & 38 & 76.0 \\
& Malar rash & 17 & 34.0 \\
& Non specific rash (Other rashes) & 72.0 \\
Photosensitivity & 36 & 54.0 \\
Skin & Cutaneous vasculitis & 27 & 34.0 \\
& Livido reticulasis & 17 & 10.0 \\
& Periungual capillary abnormalities & 5 & 8.0 \\
& Raynaud's phenomenon & 4 & 2.0 \\
& Mucosal ulceration/oral ulcer & 1 & 54.0 \\
Alopecia & 27 & 50.0 \\
Neurologic & Psychosis & 25 & 6.0 \\
& Seizure & 3 & 6.0 \\
& Headache & 3 & 16.0 \\
Cognitive dysfunction & 8 & 4.0 \\
Renal & Acute confusional state & 2 & 4.0 \\
& Hypertension & 2 & 8.0 \\
& Oedema & 4 & 16.0 \\
& Proteinuria & 8 & 60.0
\end{tabular}

Staining patterns of ANA were found homogenous in the majority (54\%) followed by fine speckled, coarse speckled, cytoplasmic and nucleoar $(18 \%, 14 \%, 6 \%, 2 \%)$ in paediatric SLE patients (Table 2). 
Table 2. Patterns of ANA By IF method among paediatrics SLE patients.

\begin{tabular}{lll}
\hline Patterns & Number & Percentage \\
\hline Homogenous & 27 & 54 \\
Fine speckled & 9 & 18 \\
coarse speckled & 7 & 14 \\
Cytoplasm & 3 & 6 \\
Nuclear & 1 & 2 \\
Absent & 3 & 3 \\
\hline
\end{tabular}

Most frequently present autoantibodies were ANA, present in $94 \%$ of patients and anti-ds-DNA in $86 \%$ patients, followed by anti RNP (46\%), anti-Sm and anti-Ro/SSA antibody in 28\%, anti La/SSB antibody in 18\% of paediatric SLE patients (Table 3).

Table 3. ENA and other autoantibodies found among childhood SLE Patients. $(n=50)$.

\begin{tabular}{lll}
\hline Autoantibodies & Number (n) & Percentage (\%) \\
\hline Anti-Ro/SSA & & \\
Absent & 36 & 72.0 \\
Present & 14 & 28.0 \\
Anti-La/SSB & & \\
Absent & 41 & 82.0 \\
Present & 9 & 18.0 \\
Anti-sm & & \\
Absent & 36 & 72.0 \\
Present & 14 & 28.0 \\
Anti-RNP & & \\
Absent & 27 & 54.0 \\
Present & 23 & 46.0 \\
ANA (IIF) & & \\
Absent & 03 & 6.0 \\
Present & 47 & 94.0 \\
Anti-ds-DNA & & \\
Negative & 07 & 14.0 \\
Positive & 43 & 86.0 \\
\hline
\end{tabular}

Hepatosplenomegaly was found in all the paediatric SLE patients as gastro-intestinal manifestations in this study. Anti-RNP and anti-SSA were significantly associated with these gastro-intestinal manifestations. (Table 4)

Table 4. Association of gastrointestinal features with ANA and ENA profile in paediatric SLE patients. $(n=23)$.

\begin{tabular}{|c|c|c|c|c|c|c|c|}
\hline \multirow[t]{2}{*}{$\begin{array}{l}\text { Clinical features } \\
\text { (Gastro intestinal features) }\end{array}$} & \multirow[t]{2}{*}{$\begin{array}{l}\text { Total } \\
\text { number }\end{array}$} & $\begin{array}{l}\text { Anti-SSA } \\
(\mathrm{N}=14) \mathrm{n}(\%)\end{array}$ & $\begin{array}{l}\text { Anti-SSB } \\
(\mathrm{N}=9) \text { n (\%) }\end{array}$ & $\begin{array}{l}\text { Anti-Sm } \\
(\mathrm{N}=14) \mathrm{n}(\%)\end{array}$ & $\begin{array}{l}\text { Anti-RNP } \\
(\mathrm{N}=23) \mathrm{n}(\%)\end{array}$ & $\begin{array}{l}\text { Multiple Anti- } \\
\text { ENA present } \\
(\mathrm{N}=18) \mathrm{n}(\%)\end{array}$ & $\begin{array}{l}\text { ANA (IIF) } \\
(\mathrm{N}=47) \text { n (\%) }\end{array}$ \\
\hline & & Present & Present & Present & Present & Present & Present \\
\hline Hepatosplenomegaly & 23 & $10(43.5 \%)$ & $04(17.4 \%)$ & $09(39.1 \%)$ & $14(60.9 \%)$ & $11(47.8 \%)$ & $22(95.7 \%)$ \\
\hline p-Value* & & $0.024 * *$ & 0.918 & 0.106 & $0.050 * *$ & 0.108 & 0.650 \\
\hline
\end{tabular}

$\mathrm{p}$ value measured by Chi-square test, $* *$ Significant

Table 5 shows the association of renal presentations with ANA and anti-ENA antibodies. In this study $60 \%$ of SLE children were presented with proteinuria. Proteinuria was associated with ANA (90\%) followed by anti-RNP (33.3\%), multiple ENA and anti-Sm. P value was significantly high with multiple anti-ENA, anti-RNP and ANA.

Table 5. Association of renal features with ENA profile and other auto antibodies in paediatric SLE. $(n=31)$.

\begin{tabular}{|c|c|c|c|c|c|c|c|}
\hline \multirow[t]{2}{*}{ Clinical features } & \multirow[t]{2}{*}{ Total number } & $\begin{array}{l}\text { Anti-SSA } \\
(\mathrm{N}=14) \mathrm{n}(\%)\end{array}$ & $\begin{array}{l}\text { Anti-SSB } \\
(\mathrm{N}=9) \text { n }(\%)\end{array}$ & $\begin{array}{l}\text { Anti-Sm } \\
(\mathrm{N}=14) \text { n (\%) }\end{array}$ & $\begin{array}{l}\text { Anti-RNP } \\
(\mathrm{N}=23) \text { n (\%) }\end{array}$ & $\begin{array}{l}\text { Multiple anti-ENA } \\
(\mathrm{N}=18) \mathrm{n}(\%)\end{array}$ & $\begin{array}{l}\text { ANA (IIF) } \\
(\mathrm{N}=47) n(\%)\end{array}$ \\
\hline & & Present & Present & Present & Present & Present & Present \\
\hline Hypertension & 4 & $00(0.0 \%)$ & $00(0.0 \%)$ & $00(0.0 \%)$ & $01(25.0 \%)$ & $00(0.0 \%)$ & $03(75.0 \%)$ \\
\hline Oedema & 8 & $01(12.5 \%)$ & $01(12.5 \%)$ & $3(37.5 \%)$ & $3(37.5 \%)$ & $2(25.0 \%)$ & $08(100 \%)$ \\
\hline Proteinuria & 30 & $8(26.7 \%)$ & $3(10.0 \%)$ & $8(26.7 \%)$ & $10(33.3 \%)$ & $8(26.7 \%)$ & $27(90.0 \%)$ \\
\hline p-Value* & & 0.659 & 0.231 & 0.659 & $0.013 * *$ & $0.054 * *$ & $0.049 * *$ \\
\hline
\end{tabular}

$* \mathrm{P}$ value reached from Chi-square test, **Significant 


\section{Discussion}

This cross sectional study was carried out with the objective of describing the frequency and patterns of ANA and frequency of ENA profile in paediatric SLE patients. Associations of ENA profile and ANA with clinical manifestations in SLE children were also observed in this cohort.

In the present study, mean age at diagnosis was $12.46 \pm$ 2.33 years and there was female preponderance which was comparable to other Indian [14], Philippine [15] and previous Bangladeshi [16] studies.

Constitutional features (92\%), arthritis/arthalgia (76\%), non-specific rashes (72\%) and renal involvement (60\%) were common clinical manifestations in this study. In an Indian study arthritis was the most common manifestation followed by constitutional, skin rash and renal involvement. [17]. Another Brazilian study had different observations. They found skin, musculoskeletal, hematological and renal as the predominant clinical manifestations in their study. [18]. These different observations may be found due to geographical and ethnic variations.

In this study ANA (IIF) was present in 94\% SLE patients where Dipti et al [19] and Weiss [20] found 100\% and $99 \%$ ANA positivity by IIF method respectively in their study. Homogenous pattern of ANA was found as the predominant (54\%), followed by fine speckled (18\%) and coarse speckled $(14 \%)$ pattern in the present study. Frodlund et al in their study found similar observations. [21]. In USA a similar study reported that homogenous and peripheral patterns were most frequent in SLE patients and only a few had speckled pattern. [22]

While analyzing the ENA profile in a review, it has been shown that anti-RNP and anti-Sm antibody were detectable in 25 to $47 \%$ and 5 to $30 \%$ of SLE patients respectively in different studies. [23]. The present study found similar result having anti RNP (46\%) commonest followed by anti-Sm and anti-SSA (28\%). Among the ENA profile anti-Sm, anti RNP, anti-SSA and anti-SSB were positive in $31 \%, 36 \%, 34 \%$ and $11 \%$ respectively in paediatric SLE patients in a Brazilian study [18] which was similar to our findings. In a previous Bangladeshi study also observed parallel result to the current study. [24] But in a Egyptian study, frequency of Anti ENA antibodies were found almost similar to present study except anti-RNP which was $10 \%$ in their study. [11]

In our study, anti-RNP was more commonly associated with constitutional features including arthritis/arthralgia, malar rash, non-specific rash, photosensitivity and proteinuria. Hoffman et al also found the associations of anti-RNP with fever, malar rash, arthritis and Raynaud's phenomenon in their study. [25] In another Brazilian study observed similar findings. They found photosensitivity, malar rash, arthritis, raynaud's phenomenon and nephritis were significantly associated with anti-RNP in their cohort. [26]. Our study found only one case of raynaud's phenomenon.

Anti-Sm was commonly present with constitutional, musculoskeletal features, oral ulcer, renal and gastrointestinal features in the current study. We also had similar result with anti-SSA. One Sweedish study found that anti-Sm antibodies were associated with oral ulcer, Reynaud's phenomenon and renal involvement. [21]. Thompson et al observed that SLE cases having anti-Sm antibody were associated with malar rash, haematological and renal involvement. [27]. In an AfroCaribbean cohort of SLE patients rash, alopecia, oral ulcers, serositis, arthritis, renal and neurological involvement were associated with anti-sm and anti-RNP antibodies. [28] Our study had similarities with the previous studies except raynaud's phenomenon, haematological, serositis, neurological and gastrointestinal features. Different ethnic background, geographical locations and age of the study population might be the reason for the discrepancy of the results.

The findings of the present study are important to predict different organ involvement in the paediatric SLE patients indicating the importance of ENA profile to forecast different manifestations early in the disease course. Identification the organ involvement early and initiation of appropriate management could minimize the morbidity and mortality of this devastating disease.

\section{Conclusion}

ANA and anti-ds DNA were positive in $94 \%$ and $86 \%$ paediatric SLE cases. Anti-ENA positivity was also found $56 \%$ in this study. Presence of ANA, anti-RNP and multiple ENA autoantibodies were significantly higher in patients with renal involvement. Anti-RNP and anti-SSA were also considerably higher in patients with gastrointestinal involvement. So, it may be concluded from this study that ENA profile positivity are suggestive of organ involvement specially gastrointestinal and renal involvement in paediatric SLE patients.

\section{Funding}

This study was funded by University Grant Commission (UGC), Dhaka, Bangladesh.

\section{Acknowledgements}

All the paediatricians and residents, department of paediatrics, Bangabadhu Sheikh Mujib Medical University. All the children with SLE and their parents.

\section{References}

[1] Hochberg MC. Updating the American College of Rheumatology revised criteria for the classification of systemic lupus erythematosus. Arthritis Rheum 1997; 40: 1725 .

[2] Egner W. The use of laboratory tests in the diagnosis of SLE. J Clin Pathol 2000; 53: 424-32. 
[3] To CH, Petri M. Is antibody clustering predictive of clinical subsets and damage in systemic lupus erythematosus? Arthritis Rheum 2005; 52: 4003-10.

[4] Rebecca ES, Stacy PA, Schanberg LE. Systemic Lupus Erythematosus, In Kliegman RM, Stanton BF, St. Geme III JW, Schor NF, Behrman, RE editors. Nelson Textbook of Pediatrics, 1st South Asia Ed. Reed Elsevier, India 2016. pp. 1176-1181.

[5] Sallai K, Nagy E, DErfalvy B, Muzes G Gergely P. Antinucleosome antibodies and Decreased Deoxyribonuclease Activity in Sere of Patients with Systemic Lupus Erythematosus. Clinical and diagnostic laboratory immunology 2005; 12: 56-59.

[6] Dipti TR, Azam MS, Sattar MH, Rahman SA. Detection of anti-nuclear antibody by immunofluorescence assay and enzyme immuno assay in childhood systemic lupus erythematosus: experience from Bangladesh. International Journal of Rheumatic Diseases 2012; 15: 121-25.

[7] Kumar Y, Bhatia A, Minz RW. Antinuclear antibodies and their detection methods in the diagnosis of connective tissue disease: a journey revisited. Diagnostic Pathology 2009; 4: 1 doi: 10.1186/1746-1596-4-1.

[8] Fritzler MJ. Clinical relevance of autoantibodies in systemic rheumatic diseases. Mol Biol Rep 1996; 23: 133-145.

[9] Philip HL, Wilfred HSW, Tsz LL, Chak SL, Tak MC, Alexander MHL et al. Relationship between autoantibody clustring and clinical subsets in SLE: cluster and association analyses in Hong Kong Chinese.' Rheumatology 2013: 52: 337-345.

[10] Silverman E, Eddy A. 'Systemic Lupus Erythematosus' in Cassidy JT, Petty RE, Laxer RM, Lindsley CB (eds), Textbook of Paediatric Rheumatology 2011, 6th Ed. Philadelphia: Saunders Elsevier, pp. 315-43.

[11] Yamad A, Gheita T, Darweesh H, klooster P, Gamal R, Faithi $\mathrm{H}$ et al. Antibodies to extractable nuclear antigens in systemic lupus erythematosus patients: correlations with clinical manifestations and disease activity. Reumatismo 2018; 70: 8591.

[12] Von Mühlen, CA, Tan EM. Autoantibodies in the diagnosis of systemic lupus erythematosus. Semin Arthritis Rheum 1995; 5: $323-58$.

[13] Emlen W, O'Neil L. Clinical significance and interpretation of Anti-nuclear antibodies: comparison of detection with immunofluroscence and enzyme linked immunosorbant assays. Arthris Rheum 1997; 40: 1612-18.

[14] Kumar S, Nair S, Rajam L. Case series of Pediatric systemic lupuserythematosus from Kerala: comparison with other Indian series. International Journal of Rheumatic Diseases 2010; 13: 391-95.
[15] Gulay CB, Dans LF. Clinical presentations and outcomes of Filipino juvenile systemic lupus erythematosus. Pediatric Rheumatology 2011; 9: 1-7.

[16] Rahman SA, Islam MI, Talukder MK, Islam MM, Haque SS, Roy RR. Presentation of childhood Systemic Lupus Erythematosus in a tertiary care hospital. Bangladesh Journal of Child Health 2014; 38: 124-129.

[17] Kosaraju K, Shenoy S, Suchithra U. A cross- sectional hospital based study of autoantibody profile and clinical manifestations in south Indian patients. Indian Journal of Medical Microbiology 2010; 28: 245-247.

[18] Liphus BL, Kiss MHB, Goldberg AC. HLA -DRB1 alleles in juvenile onsetsystemic lupus erythmatosus: renal histologic class correlations. Brazillian Journal of Medical and Biological Research 2007; 40: 591-97.

[19] Dipti TR, Azam MS, Sattar MH, Rahman, SA. Detection of Antinuclear Antibody in Childhood Rheumatic Diseases by Immunofluorescence Assay and Enzyme Immuno Assay. Bangladesh J Child Health 2011; 35: 49-52.

[20] Weiss JE. Pediatric Systemic Lupus Erythematosus: More than a Positive Antinuclear Antibody. Pediatrics in Review 2012; 33: 62-74.

[21] Frodlund M, Dahlström Ö, Kastbom A, Skogh T, Sjöwall C. Association between antinuclear antibody staining patterns and clinical features of systemic lupus erythematosus: analysis of a regional Swedish register. BMJ Open 2013; 3: e003608. doi: 10.1136/bmjopen-2013-003608.

[22] Gonzalez EN, Rothfield NF. Immunoglobulin class and pattern of nuclear fluorescence in systemic lupus erythematosus. New Eng J Med 1966; 274: 1333-1338.

[23] Migliorini P, Baldini C, Rocci V, Bombardieri S. Anti-Sm and anti-RNP antibodies. Autoimmunity 2005; 38: 47-54.

[24] Sharmin S, Ahmed S, Sattar H, Miah MRA, Chowdhury MR, Hassan MM Immunofluoresence pattern of Antinuclear Antibody and Its Association with Autoantibody profile in Systemic Lupus Erythematosus. BSMMU J 2013; 6: 141-45.

[25] Hoffman, IEA, Peene, I, Meheus, L, Huzinga TW J, Cebeacauer L, Isenberg $D$ et al. Specific antinuclear antibodies are associated with clinical features in systemic lupus erythematosus, Ann Rheum Dis 2004; 63: 1155-58.

[26] Marina M, Melissa F E, Paulo HRN, Thelma LS. Anti RNP in Sytemic lupus Erythematosus. Acta Reumatol Port 2013; 38: 136-37.

[27] Thompson D, Juby A, Davis P. The clinical significance of autoantibody porofiles in patients with systemic lupus erythematosus. Lupus 1993; 2: 15-19.

[28] Morasis SA. Isenberg DA. A study of the influence of ethnicity on serology and clinical features in lupus. Lupus 2017; 26:17-26. 